\title{
Bionic design for column of gantry machining center to improve the static and dynamic performance
}

\author{
Shihao Liu ${ }^{\mathrm{a}, *}$, Wenhua Ye ${ }^{\mathrm{a}}$, Peihuang Lou ${ }^{\mathrm{a}}$, Weifang Chen ${ }^{\mathrm{a}}$, Jungui Huang ${ }^{\mathrm{b}}$ and Lili Xiao ${ }^{\mathrm{a}}$ \\ a Jiangsu Key Laboratory of Precision and Micro-Manufacturing Technology, Nanjing University of Aeronautics \\ and Astronautics, Nanjing, China \\ ${ }^{\mathrm{b}}$ Technology Center of Wuxi Qiaolian CNC Machine Tool Co., Ltd. Wuxi Jiangsu, China
}

Received 13 November 2010

Revised 4 June 2011

\begin{abstract}
In order to improve the machining accuracy of a gantry machining center, structural bionic design for column was conducted. Firstly, the bionic design method for stiffener plate structure was established based on distribution principles of gingko root system. The bionic design method was used to improve column structure of the gantry machining center, and three kinds of bionic columns were put forward. The finite element analysis on original and bionic columns indicates that the mass of the column with the best bionic stiffener plate structure is reduced by $2.74 \%$ and the first five order natural frequencies are increased by $6.62 \%$ on average. The correctness of column's bionic design method proposed in this paper was verified by the static and dynamic experiments. Finally, the bionic principles for stiffener plate of column were concluded, which provides a new idea for updating traditional design concepts and achieving lightweight structure of machine tool components.
\end{abstract}

Keywords: Bionic design, root system, gantry machining center, column, finite element analysis, static and dynamic performance

\section{Introduction}

The creatures have biological structure with good mechanical properties after evolution of eons, which provides a lot of design prototypes and improvement methods for humans to solve the structural optimization design problem in mechanical engineering field [1,2]. For example, the researchers of Jilin University of China researched an integrated design method and optimization technology of structure parameters and work parameters of the bionic soil-loosen components through simulating the special configuration of soil animal's toe [3].Therefore, extracting the beneficial configuration principles of biological structure and applying them to the mechanical structure optimization design has become an important bionic research work, which includes stiffener plate arrangement optimization of large machine tool structure.

In traditional machine tool structure design, stiffener plate arrangement usually is "\#” shape, "X" shape or other simple shapes. Researchers mainly optimized the structural parameters [4,5] or adopted other process measures to improve the structural mechanics properties [6,7], but these research works still didn't break traditional design idea. Because of calculated by the experience, the traditional design method usually causes the problem that the machine tool's mass is too big to meet the high-efficient machining requirements of modern CNC machine tool. In recent years, although the structural bionic method has been used in optimization design of machine tool structure, it is still

\footnotetext{
* Corresponding author: Dr. Shihao Liu, Jiangsu Key Laboratory of Precision and Micro-Manufacturing Technology, Nanjing University of Aeronautics and Astronautics, Nanjing 210016, China. Tel.: +86 25 84892558; Fax: +86 25 84893351; E-mail: liushihao1102@126.com.
} 


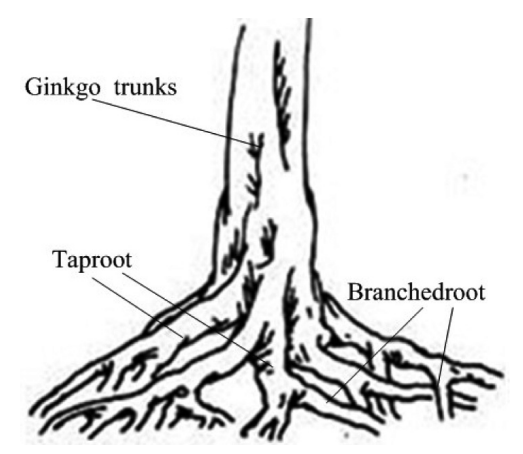

Fig. 1. Ginkgo root system structure.

in the original study stage. Zhao et al. [8] carried out structure optimization design for stiffener plate of a gantry machine tool cross-beam based on giant waterlily vein distribution, and summarized the bionic design principles of cross-beam's stiffener plate. Yang et al. [9] conducted structural bionic design for the internal structure of a machine tool column, and the static and dynamic performance of the column was improved obviously. In literature [10], bionic design of a machine tool column was conducted by using honeycomb sandwich structure, which made mass of the column reducing.

Based on the above bionic design methods of machine tool structure, this paper conducted the bionic design for the traditional stiffener plate's arrangement of a gantry machining center's column by using structural bionic method, whose inspiration came from the plant root system structure. The configuration principles of a typical plant root system structure were applied to design stiffener plate of the column, and the effect on structural lightweight and Ant-vibration performance improving were verified by finite element method (FEM), then the bionic design principles of stiffener plate were summarized.

\section{Bionic design method of machine tool column structure}

Take the stiffener plate arrangements of a machine tool column as a gradual forming process which is adaptive to a certain work condition, the column structure can gradually achieve the optimal mechanical performances under the material mass constraint. This process has certain similarity to the formation process of plant root morphology. Therefore, this paper proposed a stiffener plate bionic design method to improve machine tool column through studying the mechanics principle of plant root morphology.

\subsection{Configuration principles of ginkgo root system}

During the evolution, the biological branch structure reflects optimization theory and method for material distribution, which can use the least material to achieve more functions and ensure structural mechanical properties. Taking a typical biological branch structure (plant root system) for example, the root system not only transports nutrients but also keeps growing direction and overall stiffness. The plant root system can keep the contact between the structure and the soil under the soil load to achieve the maximum geotropism and the maximum nutrients absorbing. The above structural performance of plant root system is very similar to the stiffener plate of machine tool, so bionic design for stiffener plate can be carried out through using the distribution principles of plant root system.

The ginkgo is a kind of deciduous big arbor, whose root system is very big and extended. The roots of ginkgo grow into soil around, which have strong load-bearing capacity [11]. In order to study the distribution principles of plant root system, the gingko is taken as the research object, whose root system structure is shown in Fig. 1. The ginkgo root system is consisted of taproot and branchedroot, whose distribution is radial. The diameter of root decreases gradually along the growing direction, and each root has more sub-roots with its radius increasing so as to absorb enough nutrients from soil. 


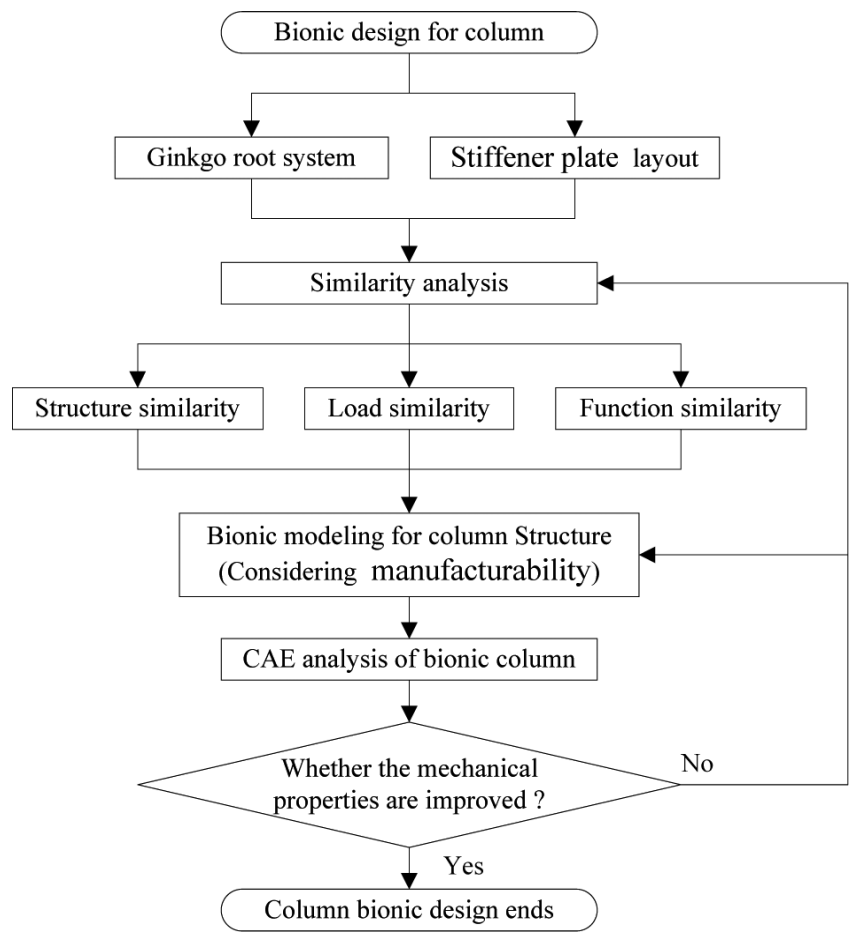

Fig. 2. Column structural bionics design method.

The ginkgo roots extend fully in soil in order to ensure certain surface stiffness to bear soil load. Similarly, the stiffener plate of machine tool column should have high stiffness under a surface load to improve machining accuracy. Therefore, the next section of this paper will build a structural bionic design method for stiffener plate of machine tool column according to configuration principles of gingko root system.

\subsection{Bionic design method of column stiffener plate arrangement}

With the tendency of high-precision and high-speed in modern CNC machine tools development, the gantry machining center's moving parts should have light mass and high Ant-vibration performance to achieve high precision under high acceleration, which use the minimum structural materials to withstand the maximum load. Ginkgo root system structure is the result of natural selection and life evolutionary, which has good mechanics properties that artificial mechanical structure can't match. The column stiffener plate's bionic structure is designed by using the configuration principles of the ginkgo root system to improve the machine tool's machining accuracy, both of which have similar structure and similar mechanical properties [12].

Taking the ginkgo root system as bionic object, the similarities (structure similarity, load similarity and function similarity) between stiffener plate structure and root system were studied, and the column stiffener plate's structure was improved according to the mechanics properties advantages of ginkgo root system. At the same time, because the root system structure is more complex than the traditional stiffener plate structure, the structural manufacturability must be considered fully when extracting its mechanical properties. Then the bionic stiffener plate structure(including arrangement, dimensions and other parameters) were obtained based on ginkgo root system, and the parameterized model of bionic column was built in CAD software. Finally, the CAE analysis for the bionic column's mechanical properties was conducted through using finite element method, if the analysis results are not satisfied, new bionic design will be conducted according to column structural bionic method that is shown in Fig. 2. 
Table 1

Material properties of HT300

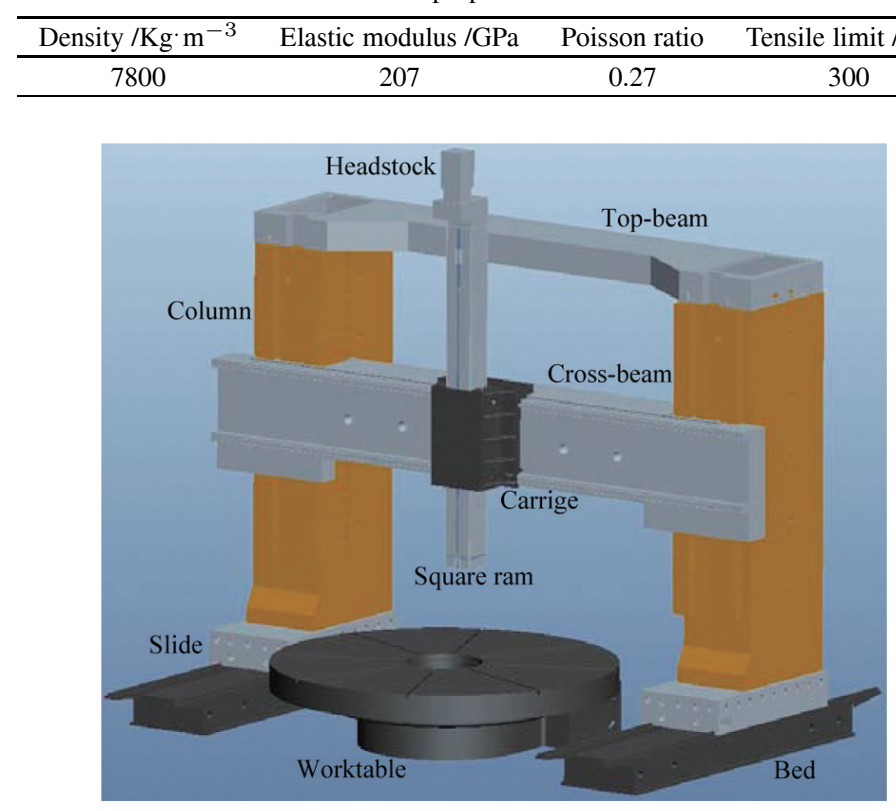

Fig. 3. 3-D model of gantry machining center.
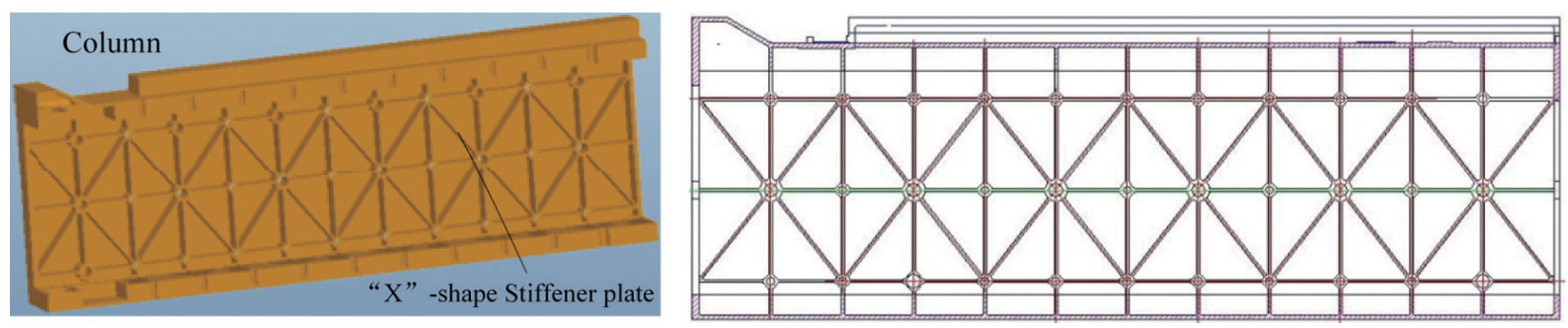

Fig. 4. The original column. (a) Stiffener plate structure of original column; (b) 2-D drawing of original stiffener plate.

\section{Bionic design of machine tool column structure}

The researched object is the column of a gantry machining center (as shown in Fig. 3) made by Wuxi Qiaolian CNC Machine Tool Co., Ltd of China, whose power capacity is $37 \mathrm{kw}$, spindle speed is $10 \sim 1500 \mathrm{rpm}$. The feed velocity of the gantry machining center is as follow: $1 \sim 4000 \mathrm{~mm} / \mathrm{min}$ in $\mathrm{X}$ axis, $1 \sim 5000 \mathrm{~mm} / \mathrm{min}$ in $\mathrm{Y} / \mathrm{Z}$ axis, and $1 \sim 2000 \mathrm{~mm} / \mathrm{min}$ in $\mathrm{W}$ axis. The length of gantry machining center is $11 \mathrm{~m}$, the width is $12 \mathrm{~m}$, and the height is $9 \mathrm{~m}$. The material of the column is HT300 whose material properties are shown in Table 1. Figure 3 shows that the column plays a role in supporting top-beam, and the cross-beam achieves linear feed motion on column. The mass, static stiffness and dynamic performance of column greatly affect the machining accuracy of the machine tool, so it is necessary to improve stiffener plate structure of column in order to improve its static and dynamic performance.

The mass of original column is $19726 \mathrm{Kg}$, and its height is $6100 \mathrm{~mm}$. The mass of top-beam is $14126 \mathrm{Kg}$, and the mass of cross-beam and headstock is $32289 \mathrm{Kg}$. The layout form of stiffener plate is " $\mathrm{X}$ " shape and distributes evenly, which is shown in Fig. 4. The structure shape of this kind stiffener plate is simple, so it is easy to cast forming.

The original stiffener plate arrangement is designed based on traditional experience only, whose influence to the static and dynamic performance is considered little, so the optimization design space is rather big. On basis of similarity principle and root system distribution principles of ginkgo, bionic design for traditional stiffener plate arrangement is conducted, and the result is shown in Fig. 5. The theoretical basis of bionic design is as follows. 
Table 2

Bionic type columns

\begin{tabular}{cl}
\hline Bionic type & \multicolumn{1}{c}{ Structural characteristics } \\
\hline A & Bionic stiffener plate according to ginkgo root system (as shown in Fig. 5) \\
B & Bionic stiffener plate according to ginkgo root system ${ }^{+}$reinforcement plates in guide's load area (as shown in Fig. 6) \\
C & Bionic stiffener plate according to ginkgo root system ${ }^{+}$reinforcement plates in guide's load area \\
& + reinforcement plates in load area of top part (as shown in Fig. 7) \\
\hline
\end{tabular}
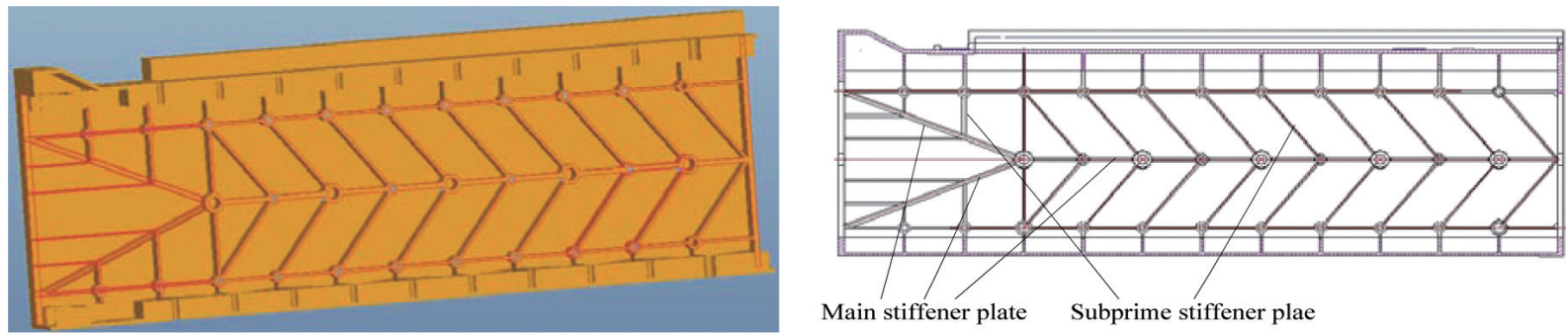

Main stiffener plate Subprime stiffener plae

Fig. 5. The bionic type column. (a) Stiffener plate structure of bionic column; (b) 2-D drawing of bionic stiffener plate.

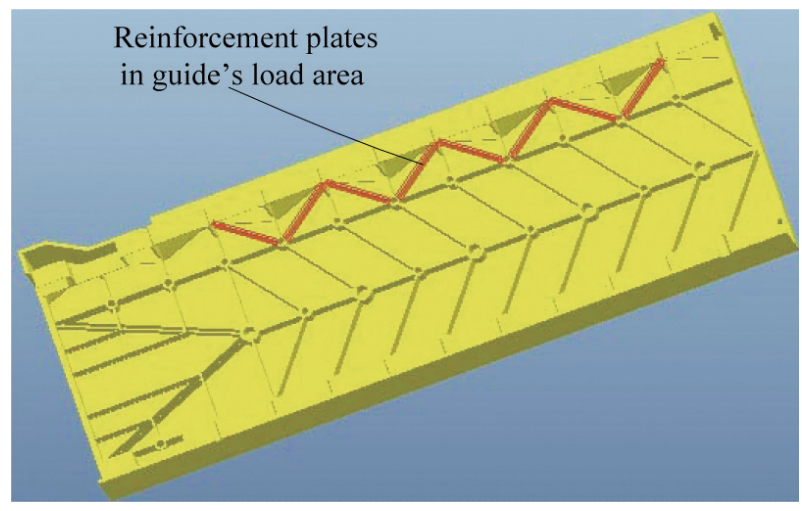

Fig. 6. The bionic type column B.

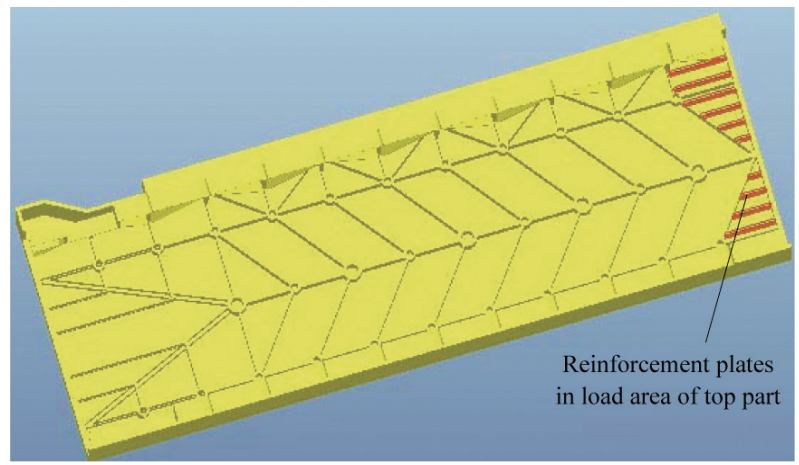

Fig. 7. The bionic type column C.

(1) Root system's growing direction - distribution direction of stiffener plate

Ginkgo root system mainly bears its own weight, soil load and other external load. By using materials effectively as the prerequisite, ginkgo root can ensure overall stiffness and planeness to absorb nutrients adequately. Therefore, in order to improve the static and dynamic performance of column, the distribution 
principles of ginkgo root system can be used to design stiffener plate arrangement.

(2) Taproot - main stiffener plate

In order to effectively and evenly transmit the external load, ginkgo's taproot always grows along the shortest route in load-bearing area. Therefore, the main stiffener plates are arranged along the gradient direction between support area and load area, which grows from the support parts to the maximum deformation area (the top part of column).

(3) Branchedroot - subprime stiffener plate

Ginkgo's branchedroot connects adjacent taproot and spreads along the growing direction, which can disperses the external load. Therefore, subprime stiffener plates are arranged among main stiffener plates and divide column interior space evenly, which are parallel or interlaced.

(4) Adaptive growth - reinforcement plate

The ginkgo root system is formed in long-term adaptive development, so it has good mechanical properties. Based on the adaptive growth of ginkgo root system, the reinforcement plates are arranged on the load-bearing guide to increase the capacity of load-bearing. The stiffener plates of non-load area and small deformation area can be removed properly in order to achieve lightweight design of column [13].

Considering the processing manufacturability, three kinds of bionic stiffener plates are put forward, which are shown in Table 2. And the influences of stiffener plate arrangement on the structural performance will be studied in following content.

\section{Comparative study of original and bionic type columns}

\subsection{The finite element analysis of column structure}

The 3-D models of above three bionic type columns were built by using CAD software. In order to reduce the number of finite element mesh and computing time, the columns' structure were simplified reasonably by removing the small round hole, small chamfering and small fillet. Then the 3-D models of columns were imported into ANSYS software to build finite element models. The column is an important support part of the gantry machining center, so its load-bearing is rather complex. The load imposed on the top of the column is $69217 \mathrm{~N}$, which is the half of top-beam's gravity. The load imposed on the middle of the column is $118216 \mathrm{~N}$, which is the half gravity of cross-beam, carriage, headstock and tool. During the machining process, the maximum milling force in $\mathrm{X}$ and $\mathrm{Y}$ direction is $40000 \mathrm{~N}$ respectively. The above forces' synthesis draw is shown in Fig. 8. The column is fixed on the slider by bolts, so the fixed constraints shown in Fig. 8 are imposed on the threaded holes of the bottom of the column. Therefore, constraints and boundary conditions of bionic type column are shown in Fig. 8. The CAE analysis and results evaluation of bionic columns were carried out in accordance with technical route as shown in Fig. 2.

In order to ensure the design requirements of strength and stiffness, static analysis on column was conducted in this paper. Statics analysis on column is used to calculate the stress and deformation under constant load. Through finite element analysis, the maximum deformation and stress distribution of original and bionic type columns can be obtained.

The dynamic performance of column affects machining accuracy greatly, so improving the natural frequency is an effective measure to improve its Ant-vibration performance. Because the low order natural modal shape affects structural vibration greatly, the modal analysis of column was conducted to extract the first six order modals.

\subsection{Discussion of finite element analysis results}

After conducting the statics and modal analysis on above three kinds of bionic type columns and original column, and considering the structural manufacturability, the analysis results are as follows. 


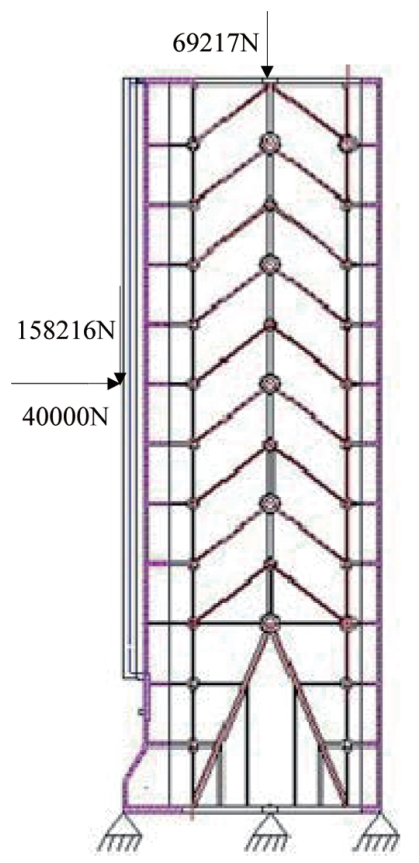

Fig. 8. Constraints and boundary conditions of bionic type column.

\subsubsection{Results of static analysis (as shown in Figs 9-11)}

The maximum deformation area locates in the top interface between column and top beam. The maximum deformation area of bionic type $\mathrm{B}$ and $\mathrm{C}$ are more concentrated than other types, and the maximum deformation area of bionic type A is the biggest. The maximum deformation of three bionic type columns are reduced by $15.05 \%$, $11.48 \%$ and $16.38 \%$ respectively compared to the original column. The stress value is von-Mises stress (as shown in Eq. (1)) of static finite element stress, namely the von-Mises stress is taken as the evaluation standard for octohedral shear stress theory (The fourth strength theory). Figures 9 and 10 show that the maximum stress locates in the corner area of column's bottom, and the maximum stress of three bionic type columns are reduced by $5.29 \%, 10.22 \%$ and $8.24 \%$ respectively. The above analysis results show that increasing the number of stiffener plates in load area can reduce the maximum stress.

$$
\sigma_{\text {von }_{m} \text { ises }}=\frac{1}{\sqrt{2}} \sqrt{\left(\sigma_{1}-\sigma_{2}\right)^{2}+\left(\sigma_{2}-\sigma_{3}\right)^{2}+\left(\sigma_{3}-\sigma_{1}\right)^{2}} \leq[\sigma]
$$

\subsubsection{Structural mass analysis}

All columns' masses with different stiffener plate structure are shown in Fig. 12. Compared with the original column, the mass of three bionic type columns are reduced by $3.96 \%, 2.74 \%$ and $1.32 \%$, and the mass of bionic type A is reduced mostly $(781 \mathrm{Kg})$.

\subsubsection{Modal shape analysis}

By extracting first six order modals of original and bionic type columns (as shown in Table 3), their dynamic performance were compared. Table 3 shows that first five natural frequencies of three bionic type columns are increased by $5.78 \%, 6.62 \%$ and $6.32 \%$ on average, the sixth natural frequency are reduced, but the effect of high order modal can be neglected. The first three order modal shapes of original and bionic type columns are generally same, which are bending vibration in the center of column. The fourth, fifth and sixth orders modal shapes of original column are torsional vibration, while the bionic type columns' are protruding vibration in bottom of column, which are far away from load areas. 


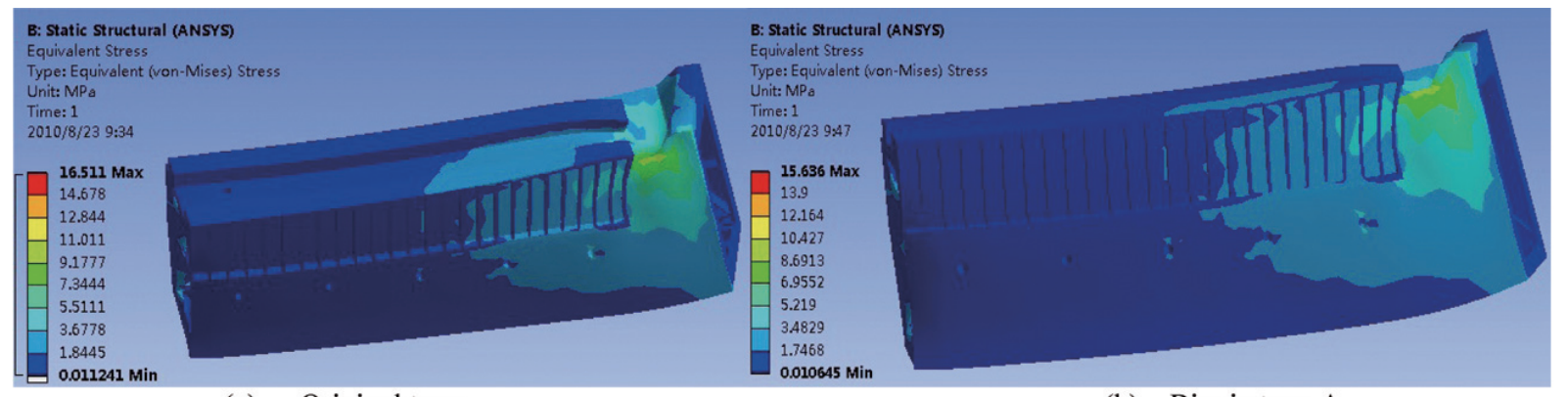

(a) Original type

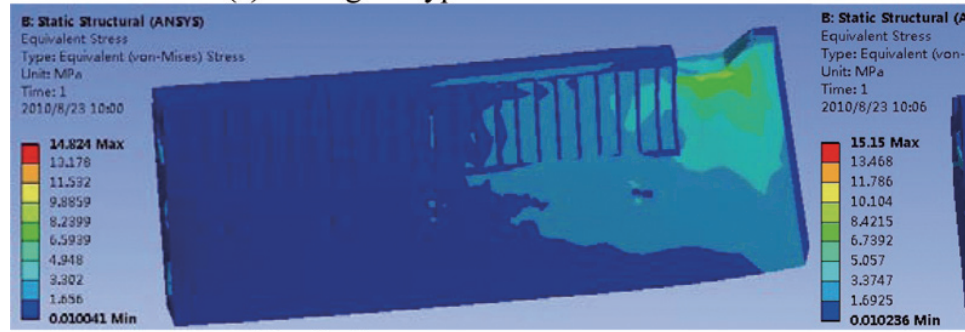

(c) Bionic type B (b) Bionic type A

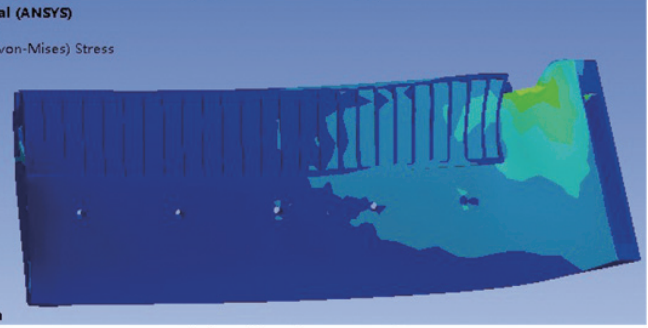

(d) Bionic type $\mathrm{C}$

Fig. 9. The von-Mises stress of columns.

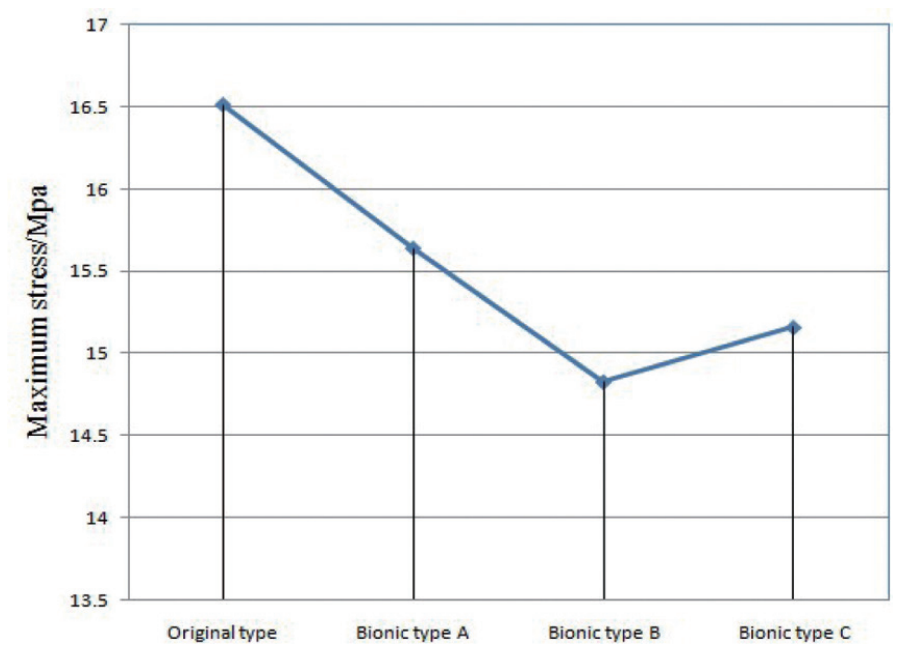

Fig. 10. The maximum stress graph.

\subsubsection{Manufacturability analysis of column structure}

Compared with the original parallel stiffener plate, the stiffener plates of bionic type columns are more complex, but all of them can be casted forming. Because the space between the stiffener plates of bionic type column is bigger than original column, they are easy to cast forming. The mass of bionic type columns are reduced so that it can save materials and cost. The manufacturability of bionic type $\mathrm{A}$ is the best, $\mathrm{B}$ is second, and $\mathrm{C}$ is the most complicated.

\subsubsection{Results analysis of column's bionic design}

Based on the above analysis results, the mass of the columns designed by the gingko root system is reduced, the non-deformability is improved, and the first five order natural frequencies are increased. Therefore, bionic type stiffener plate can make column achieve lightweight structure and improve static and dynamic performance. 


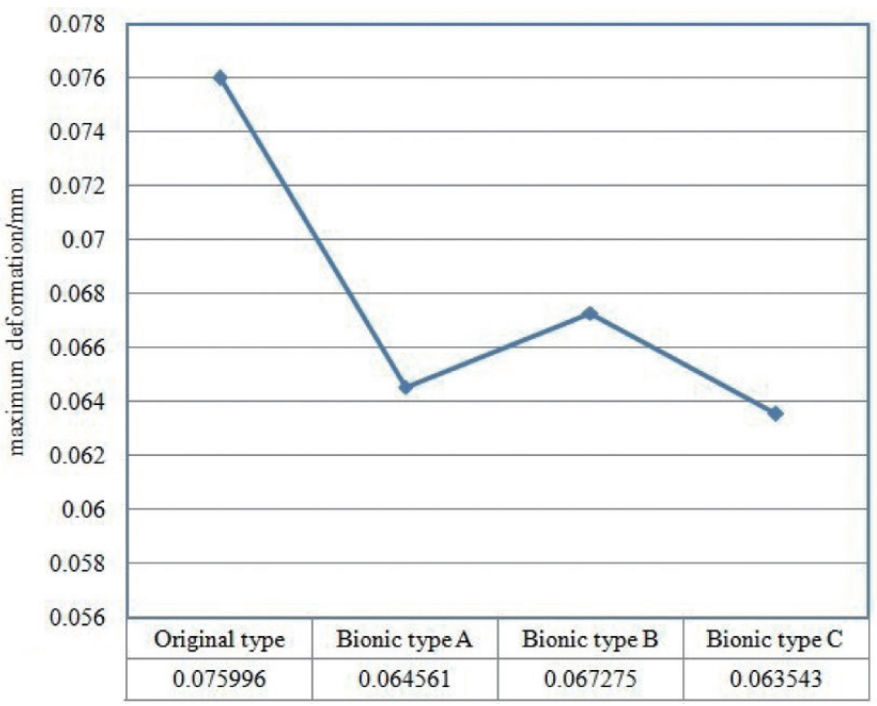

Fig. 11. The maximum deformation graph.

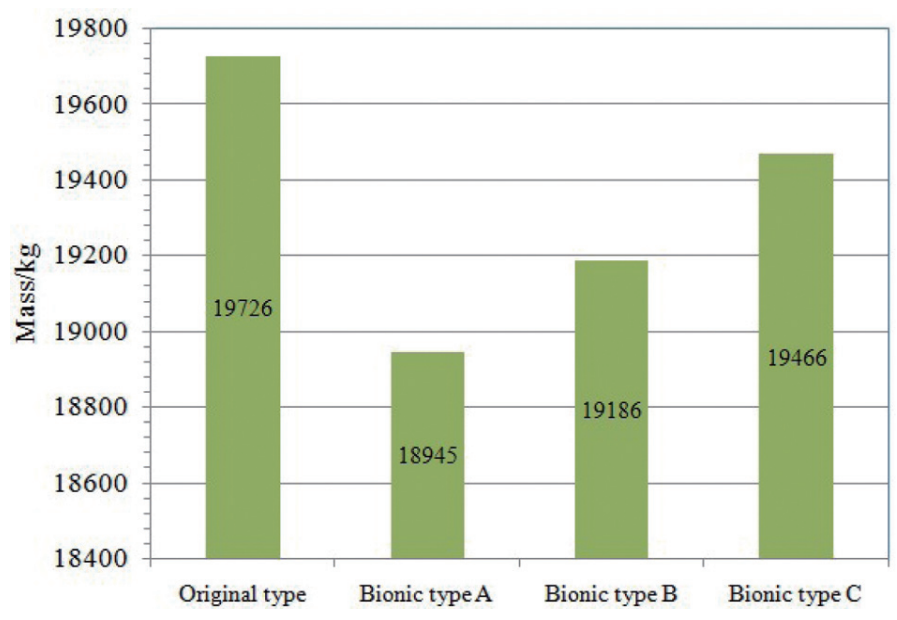

Fig. 12. Columns' mass graph.

Among the three kinds of bionic type columns, although the mass of bionic type A column is the smallest and its manufacturability is the best, its average natural frequency of the first five orders is the lowest and maximum stress is the biggest. The maximum deformation of bionic type $\mathrm{C}$ column is the smallest, but its manufacturability is the most complicated and mass is the biggest. Considering the factors mentioned above, column B can be said to be the best among all considered. Figure 13 shows the physical model of gantry machining center with bionic type B column. The column with bionic design is assembled well on complete machine center, which ensures the rigidity and machining precision of the machine tool. Therefore, the bionic design method proposed in this paper has high engineering practicability.

\subsection{Experimental validation for the column's bionic design}

In order to validate the correctness of column's finite element simulation analysis and bionic design, static and dynamic experiments on the original type and three bionic type columns were carried out in Wuxi Qiaolian CNC Machine Tool Co., Ltd of China. The purpose of the static experiment is to obtain the column's mass and maximum 
Table 3

First 6 order natural frequencies/Hz

\begin{tabular}{ccccc}
\hline Orders & Original type & Bionic type A & Bionic type B & Bionic type C \\
\hline 1 & 87.7 & 101.8 & 100.9 & 98.8 \\
2 & 132.1 & 147.1 & 146.3 & 143.3 \\
3 & 143.8 & 152.4 & 154.2 & 156.3 \\
4 & 164.1 & 165.4 & 167.2 & 167.4 \\
5 & 168.3 & 169.6 & 173.5 & 174.2 \\
6 & 190.9 & 178.5 & 184.7 & 183.9 \\
\hline
\end{tabular}

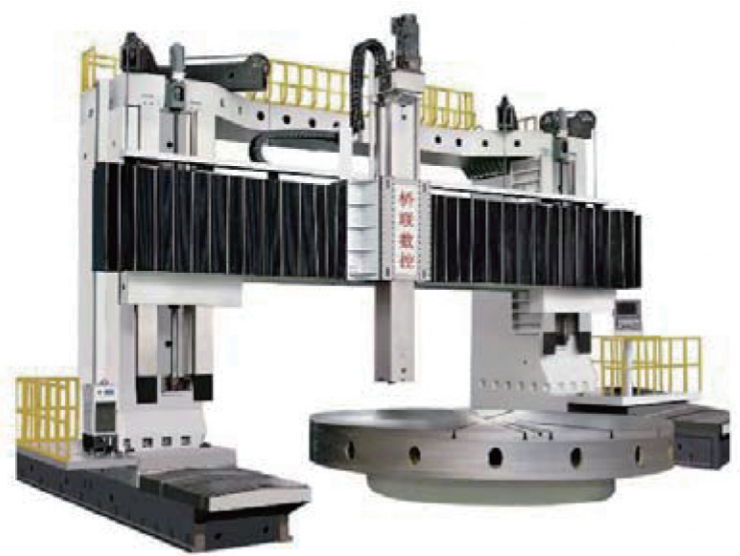

Fig. 13. Physical model of gantry machining center.

stress and maximum deformation under the actual working conditions. In the process of static experiment, static loads were applied on column by assistor, then the maximum stress and maximum deformation were obtained by stress sensor and displacement sensor. The purpose of dynamic experiment is to obtain the first six orders natural frequencies of column, and the principle model of dynamic experiment is shown in Fig. 14. The dynamic experiment was carried out in closed lab in room temperature. The test instrument is DATRAN dynamic analyzer(as shown in Fig. 15) produced by LDS company of America, and the analysis software is MESCOPE that matches the DATRAN dynamic analyzer. After selecting proper test points on column, the dynamic test and analysis system was installed properly according to the principle model diagram, then the excitation force signal and corresponding response signal of each point can be obtained. With the modal analysis software, the transfer function of each test point can be analyzed, and the column's natural frequencies can be indentified through fitting the transfer function curves. After completing the static and dynamic experiments, the contrast between finite element analysis results and experimental results of column's static and dynamic performance parameters is shown in Table 4 . Table 4 indicates that all the errors between finite element analysis results and experimental results are about 5\%, which proves that all the finite element simulation calculations done are correct and the bionic design method for column is reasonable and feasible.

\section{Conclusions and future works}

(1) The root system structure of biological branching structure can be used to improve traditional stiffener plate. According to the similarity principles, the method of extracting configuration principles or mechanical properties of root system structure to apply in the bionic design of machine tool structure can achieve structure lightweight, which has important theoretical study and engineering application value.

(2) By comparing the static and dynamic performance of original type column with bionic columns, bionics principles of stiffener plate arrangement were summarized as follows: in order to transfer loads effectively, the main stiffener plate should be arranged along the gradient direction between support area and maximum deformation area; in order to improve the static and dynamic performance of column structure, the subprime 
Table 4

Contrast between finite element analysis results and experiment results

\begin{tabular}{|c|c|c|c|c|c|}
\hline Static and dynamic performance & & Original type & Bionic type $\mathrm{A}$ & Bionic type $\mathrm{B}$ & Bionic type $\mathrm{C}$ \\
\hline \multirow[t]{2}{*}{ Mass/Kg } & Simulation result & 19726 & 18945 & 19186 & 19466 \\
\hline & Experimental result & 19977 & 19346 & 19477 & 19879 \\
\hline \multirow[t]{2}{*}{ Maximum stress/MPa } & Simulation result & 16.511 & 15.636 & 14.824 & 15.15 \\
\hline & Experimental result & 15.91 & 14.98 & 14.39 & 14.63 \\
\hline \multirow{2}{*}{ Maximum deformation/mm } & Simulation result & 0.075996 & 0.064561 & 0.067275 & 0.063543 \\
\hline & Experimental result & 0.074 & 0.063 & 0.065 & 0.062 \\
\hline \multirow[t]{2}{*}{ The second order natural frequency/Hz } & Simulation result & 132.1 & 147.1 & 146.3 & 143.3 \\
\hline & Experimental result & 129.7 & 149.4 & 150.8 & 149.1 \\
\hline \multirow[t]{2}{*}{ The third order natural frequency/Hz } & Simulation result & 143.8 & 152.4 & 154.2 & 156.3 \\
\hline & Experimental result & 141.5 & 150.4 & 158.9 & 160.8 \\
\hline \multirow[t]{2}{*}{ The fourth order natural frequency/Hz } & Simulation result & 164.1 & 165.4 & 167.2 & 167.4 \\
\hline & Experimental result & 166.8 & 168.9 & 172.6 & 172.3 \\
\hline The sixth order natural frequency/Hz & Experimental result & 188.2 & 182.1 & 189.4 & 188.5 \\
\hline
\end{tabular}

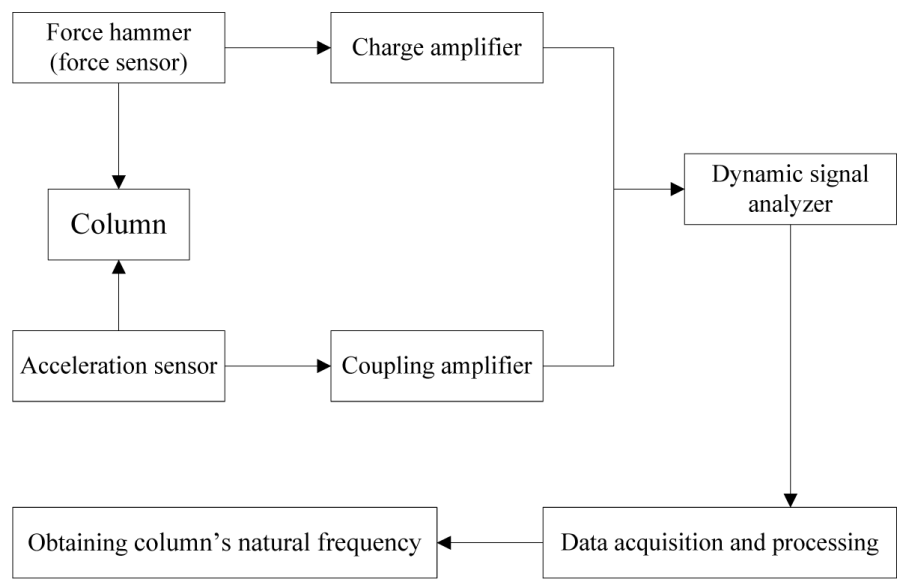

Fig. 14. Principle model of dynamic experiment.

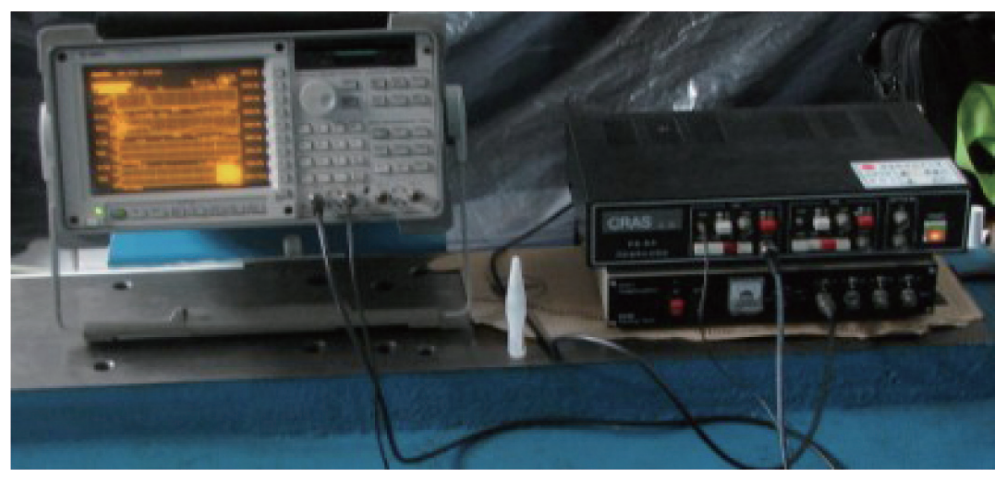

Fig. 15. Dynamic signal analyzer. 
stiffeners should be arranged perpendicularly to the load-bearing area among the main stiffener plates, and the number of stiffener plates in support area and main load area should be increased; in order to achieve material optimal distribution and optimum performance, the stiffener plates of non-load area and small deformation area can be removed properly, which affect overall stiffness little.

(3) This paper had carried out bionic design for stiffener plate arrangement of a machine tool column, so the column achieved lightweight design, and its static and dynamic performance was improved. Because the structure of bionic type stiffener plate is more complex than traditional stiffener plate, the technology how to simplify the machining manufacturability of bionic structure so as to improve the engineering practicability will be further researched.

\section{Acknowledgment}

We are grateful for the financial support by prospective study project of Jiangsu provincial industry-universityresearch institute (Project number: BY2009102).

\section{References}

[1] Y.X. Lu, Significance and progress of bionics, Journal of Bionic Engineering 1(1) (2004), 1-3.

[2] M.H. Dickinson, Bionics: Biological insight into mechanical design, Proceedings of the National Academy of Sciences of the United States of America 96(25) (1999), 14208-14209.

[3] L.Q. Ren, Biomimetic research progress of anti-adhesion and anti-resistance of terrain machinery, Science in China(Series E:Technological Sciences) 38(9) (2008), 1353-1364.

[4] P.E. John Higgins, P. Wegner, A. Viisoreanu el a1., Design and testing of the minotaur advanced grid-stiffened fairing, Composite Structures 66 (2004), 339-349.

[5] B. Gosowski, Non-uniform torsion of stiffened open thin-walled members of steel structures, Journal of constructional steel research 63(6) (2007), 849-865.

[6] M. Rahman, M.A. Mansur and Z. Feng, Design fabrication and evaluation of a steel fibre reinforced concrete column for grinding machines, Materials and Design 16(4) (1995), 205-209.

[7] S.H. Chang, P.J. Kim, D.G. Lee et al., Steel-composite hybrid headstock for high-precision grinding machine, Composite Structures 53(1) (2001), 1-8.

[8] L. Zhao, W.Y. Chen and J.F. Ma, Structural bionic optimization of stiffening ribs of a machine tool crossbeam based on giant waterlily vein distribution, High Technology Letters 19(9) (2008), 806-810.

[9] Y.B. Yang, W.Y. Chen and D.H. Zhao, Bionic design of column structure of machine tool for high specific stiffness, Journal of Beijing University of Aeronautics and Astronautics 34(9) (2008), 991-994.

[10] D.I. Kim, S.C. Jung, J.E. Lee el a1., Parametric study on design of composite-foam-resin concrete sandwich structures for precision machine tool structures, Composite and Structures 75 (2006), 408-414.

[11] S.J. Sun, R.Z. Gu, R.C. Cong et al., Effects on root, shoot and leaf growth and water status of ginkgo biloba with two tronsplanting modes, Scientia Silvae Sinicae 44(10) (2008), 35-42.

[12] J.F. Ma, W.Y. Chen, L. Zhao el a1., Elastic buckling of bionic cylindrical shells based on bamboo, Journal of Bionic Engineering 5 (2008), $231-238$.

[13] H.J. Jiao, Y.D. Zhang and W.Y. Chen, The lightweight design of low RCS pylon based on structural bionics, Journal of Bionic Engineering 7(2) (2010), 182-190. 

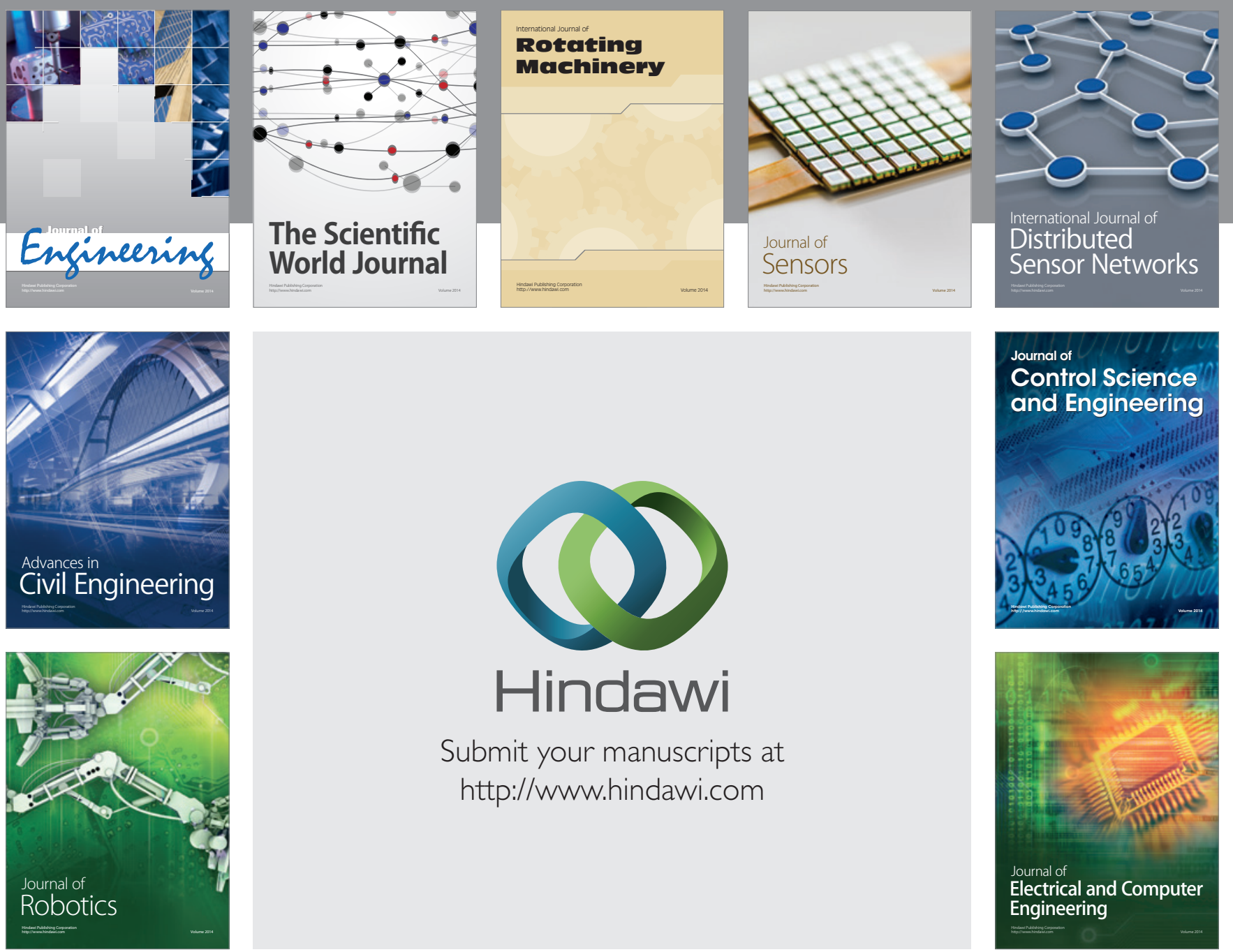

Submit your manuscripts at

http://www.hindawi.com
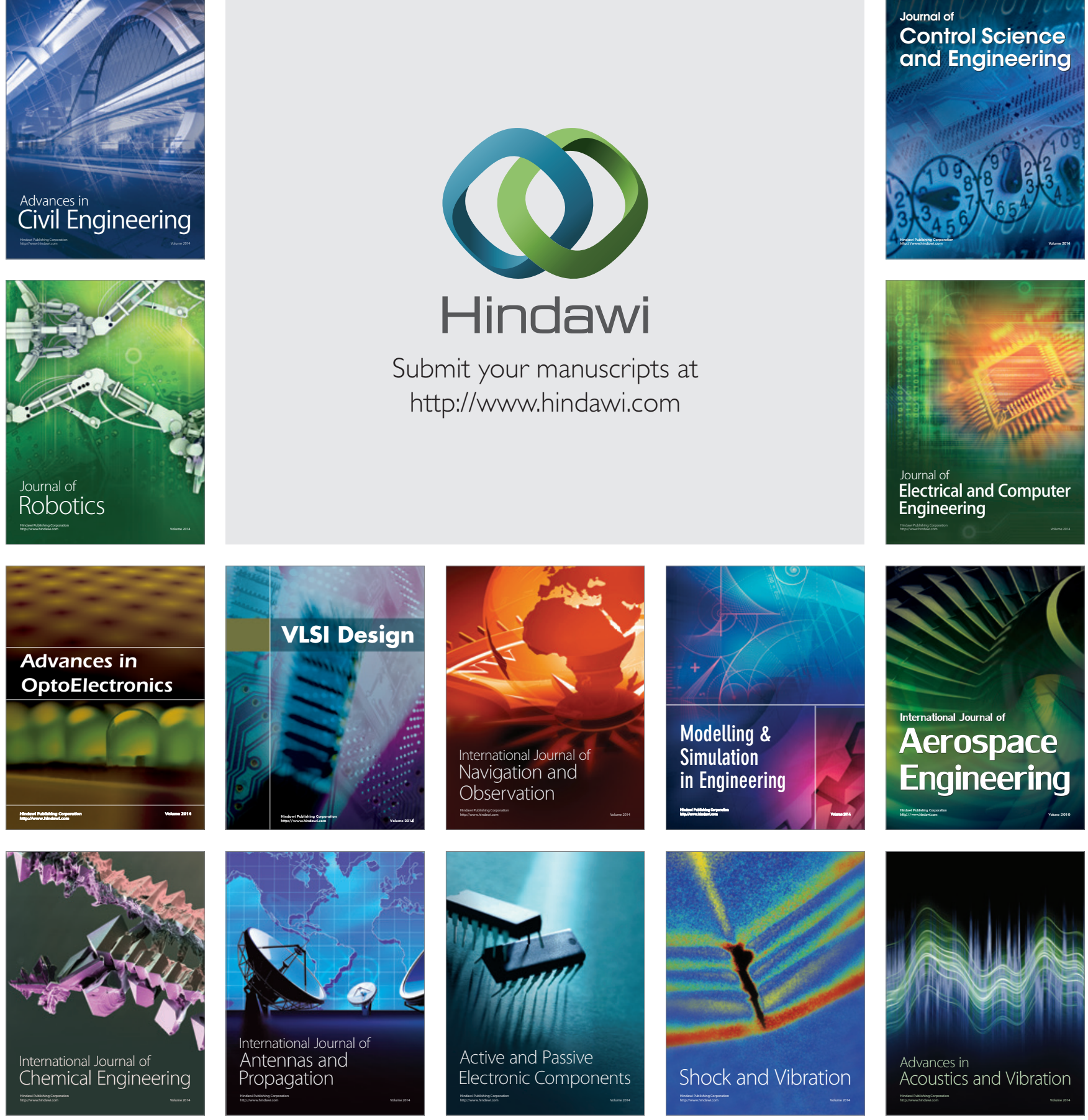